\title{
Construir la ciudadanía colectivamente: prácticas urbanas de una asamblea popular en Buenos Aires, Argentina
}

\author{
Building citizenship collectively: urban practices of \\ a popular assembly in Buenos Aires, Argentina
}

\author{
Mónica Farías ${ }^{1}$ y Fernanda Valeria Torres ${ }^{2}$ \\ Fecha de recepción: 01-01-2021 - Fecha de aceptación: 06-07-2021 \\ Hábitat y Sociedad (ISSN 2173-125X), n. ${ }^{\circ}$ 14, noviembre de 2021, pp. 11-31. \\ https://doi.org/10.12795/HabitatySociedad.2021.i14.02
}

\begin{abstract}
Traditional ideas about citizenship in their liberal conception emphasize the role played by the individual as the holder of rights and duties. These ideas have been strongly questioned by various currents of thought and from some fields of studies, such as urban studies. In this paper we seek to contribute to these debates by analyzing the urban practices of a popular assembly in the Autonomous City of Buenos Aires (CABA-Argentina). These practices are enmeshed in disputes between the old and the new, the public and the private, and the visible and invisible, configuring citizenships that promote ways of understanding and building more participatory and democratic cities.

We analyze the activities of "making visible" and activism in relation to the homelessness problem as well as the Assembly's intention of building an urban habitat anchored in the decommodification of the city and in collective projects. We conclude that this case testifies to the construction of citizen experiences that have great potential to displace the individualistic corset with which citizens' rights are usually defined and defended.
\end{abstract}

\section{Key words}

Popular Assemblies; urban habitat; urban citizenships; Argentina

\section{Resumen}

Las ideas tradicionales sobre la ciudadanía en su concepción liberal enfatizan el papel que juega el individuo como titular de los derechos y deberes. Estas ideas han sido fuertemente cuestionadas por diversas corrientes de pensamiento y desde algunos campos de estudios, como el de los estudios urbanos.

Buscamos aportar a dichos debates a partir del análisis de las prácticas urbanas de una asamblea popular en la Ciudad Autónoma de Buenos Aires (CABA-Argentina), las cuales ponen en juego disputas entre lo viejo y lo nuevo, lo público y lo privado y lo visible e invisible, configurando ciudadanías que promueven maneras de comprender y gestionar ciudades más participativas y democráticas.

Con una aproximación metodológica cualitativa, basada en un período de investigación desarrollado durante 2013 y 2014, se analizan las actividades de visibilización y militancia en relación con la problemática de estar en situación de calle y la propuesta de la Asamblea de construcción de un hábitat urbano anclado en la desmercantilización y en proyectos colectivos. Concluimos que el caso atestigua la construcción de experiencias ciudadanas que poseen gran potencialidad para desplazar el corsé individualista con el que habitualmente se definen y se defienden los derechos ciudadanos.

\section{Pallabras clave}

Asambleas populares; hábitat urbano; ciudadanías urbanas; Argentina

\footnotetext{
1 Lda. en Geografía (Universidad de Buenos Aires), Magister y Doctora en Geografía (Universidad de Washington); becaria postdoctoral del Consejo Nacional de Investigaciones Científicas y Técnicas (CONICET), en el Instituto de Geografía de la Universidad de Buenos Aires, y docente del Departamento de Geografía de la Universidad de Buenos Aires. E-mail: monicafarias@filo.uba.ar. ORCID: orcid.org/0000-0001-9080-6603

2 Lda. en Sociología, Mag. en Ciencias Sociales y Humanidades (UNQ) y Dra. en Ciencias Sociales (UNLP); Investigadora Adjunta CONICET y Profesora Adjunta UNLP. Centro de Investigaciones Socio-Históricas-CISH/ Instituto de Investigaciones en Humanidades y Ciencias Sociales-IdIHCS/ Facultad de Humanidades y Ciencias de la Educación-FaHCE/ Universidad Nacional de La PlataUNLP; E-mail: ftorres@fahce.unlp.edu.ar. ORCID: orcid.org/0000-0002-2046-0974
} 


\section{Introducción}

Las formulaciones en torno a la ciudadanía propia de los regímenes liberales y representativos la vinculan a mediaciones entre el Estado y la sociedad civil expresadas en derechos y obligaciones individualmente entendidos. Hablar de ciudadanía impone comenzar con las ideas de Thomas Humphrey Marshall, quien, en 1950, fue uno de los pioneros en proponer un análisis histórico de la evolución de la figura del ciudadano. Por ciudadanía entiende la plena pertenencia a una comunidad, ligada a la participación de los individuos en la determinación de las condiciones de su propia asociación. La ciudadanía, desde esta formulación liberal, se asocia a un estatus que garantiza a los individuos iguales derechos y deberes, libertades y restricciones, poderes y responsabilidades. Se enfatiza el papel que juega el individuo, que es el titular de los derechos y deberes. Esta corriente se opone a la noción de identidades fijas, como la posición social, y considera que el individuo asume la capacidad moral y política de definir sus propios fines, realizar sus propias elecciones informadas y perseguir su bienestar. Estos supuestos y estas visiones en torno a las maneras de definir nuestra pertenencia a la comunidad política se han enraizado en normativas y modalidades de participación y demandas de derecho en las democracias occidentales. Sin embargo, diversos debates han evidenciado sus límites, los más importantes provienen del multiculturalismo, el feminismo y el pensamiento descolonial (Kimlicka y Norman, 1997; Mouffe, 1999; Mignolo, 2006). Un escenario privilegiado en el que se ha reactualizado dicho debate, es en el campo de los estudios urbanos. Algunos autores proponen la ciudadanía urbana como una prolongación de la ciudadanía social (Donzelot, 2012), del mismo modo que esta fue, de acuerdo a Marshall, una prolongación de la ciudadanía política. Otros autores, como veremos en el apartado correspondiente, avanzaron en identificar los procesos contradictorios que supone la democratización y la urbanización, delineando diferentes tipos de ciudadanos urbanos y resaltando el rol de los residentes en las periferias segregadas que luchan por su incorporación en la comunidad política (Holston, 2009).

En este trabajo proponemos aportar a dichos debates, analizando ciertas prácticas y sentidos diferenciales en torno a la ciudad y las maneras de habitarla y reflexionar en torno a sus implicancias en términos de ciudadanía. Creemos que en las prácticas urbanas de ciertas experiencias movimientistas en, desde y por la ciudad, se perfilan demandas de participación populares y de definición de los sujetos de la ciudadanía que disputan los usos del espacio urbano y exceden, tensionan y/o cuestionan las premisas liberales.

El fenómeno de las asambleas barriales surgidas en la Ciudad Autónoma de Buenos Aires (CABA) luego de la crisis del 2001, ofrece un campo de estudios que permite cuestionar las ideas de ciudadanía enraizadas en concepciones liberales, así como repensar las prácticas ciudadanas urbanas. Las asambleas, durante todo el 2002 y parte del 2003, contribuyeron grandemente a la dinamización de la participación política de sectores con y sin experiencia política previa. Integradas mayoritariamente por personas pertenecientes a la clase media, algunos con filiación partidaria, otros no, dieron lugar a formas organizativas basadas en la proximidad física, en donde la figura del "vecino" se resignifica, y pasa de asociarse a una concepción de ciudadanía individualista, a una en donde ser vecino implica ser parte de una comunidad con intereses compartidos (Quintar y Zusman, 2003). Representaron, además, 
una instancia de puesta en práctica de una idea de ciudadanía que excedía la de ser meros portadores de derechos, para encarnarse en una ciudadanía activa, en donde los sujetos son protagonistas y hacedores de la vida política (Landa, 2005).

Se propone analizar las prácticas de una de dichas asambleas, que continúa su actividad hasta el día de la fecha, resignificando, como veremos, sus marcas de origen: la Asamblea Popular Plaza DorregoSan Telmo (de aquí en adelante "AST"), en CABA. Atenderemos a sus estrategias de visibilización y ciudadanización, relacionadas a la problemática de personas viviendo en situación de calle, analizando los resultados de una investigación cualitativa realizada durante los años 2013-2014. Las personas en situación de calle (PSC), por tratarse de un sujeto que se encuentra marginado en múltiples sentidos (económico, social, político, habitacional, etc.) y cuya marginalidad es invisibilizada y/o naturalizada constantemente, consideramos que tensiona de lleno la pretendida universalidad e igualdad de los principios ciudadanos.

Proponemos, en un primer lugar, repasar ciertas propuestas teóricas para dar cuenta de las ciudadanías urbanas (Dagnino, 2003; Chaterjee, 2006; Holston, 2009; Leitner y Strun, 2014) junto con la revisión de bibliografía abocada al surgimiento de las asambleas populares barriales en CABA, alrededor de la crisis de 2001, para desembocar en la actualidad de la experiencia de la AST.

Las acciones barriales protagonizadas por la AST en la ciudad desde 2002, desarrollan nuevos espacios de encuentro donde se juegan diversas disputas:

- Entre lo viejo y lo nuevo: reivindicar la memoria del barrio frente al avasallamiento de políticas urbanas "empaquetadas" (pariendo nuevas formas de convivencia barrial y de vecindad).

- Entre lo público y lo privado: construcciones territoriales en el barrio que discuten la creciente privatización e individualización de la ciudad en pos de propiedades comunitarias y colectivas.

- Entre lo visible y lo invisible: identificar los problemas que no se ven o se ocultan, que se niegan desde ciertas formulaciones políticas y, sobre todo, desde las políticas públicas.

Desarrollaremos un análisis de las acciones y prácticas de la AST en dichos registros, en pos de identificar posibilidades y dificultades para gestar ciudadanías urbanas que disputan una manera de comprender y gestionar ciudades más participativas y democráticas desde sentidos comunes populares. En el trabajo nos detendremos en analizar la manera mediante la cual la AST comprende a las PSC en tanto sujetos de derecho y, asimismo, propende a una colectivización de dichos derechos, interpelando el orden urbano excluyente y mercantilizado.

En el apartado que sigue, nos detenemos en el surgimiento de las asambleas populares en el contexto de la crisis del verano de 2001-2002 en Argentina y presentamos algunos de los abordajes teóricos que se ocuparon de ellas. En el siguiente, desarrollamos el marco teórico-metodológico para luego presentar nuestro caso de estudio, la Asamblea Popular Plaza Dorrego-San Telmo. Luego, nos detenemos en los modos en los que las prácticas de esta asamblea tensionan el alcance del concepto de ciudadanía y proponen otros modos de pensarla. Cerramos con algunas reflexiones finales en torno a la potencialidad de las prácticas urbanas, como las analizadas en el caso de estudio, para repensar y construir otros tipos de ciudadanías. 


\section{Emergencia y abordaje de las Asambleas Populares}

Las asambleas populares fueron organizaciones y en algunos casos aún son de alcance barrial que surgieron a partir del encuentro de la gente en el espacio público durante las jornadas de diciembre de 2001 en el marco de las movilizaciones conocidas como "el Argentinazo". Las asambleas funcionaron como espacios de deliberación e intercambio mediante prácticas horizontales de democracia participativa. En algunos casos, se limitaron a la búsqueda de soluciones a los problemas concretos de la gente que las integraba y/o de los vecinos del barrio. Por ejemplo, se organizaron "bolsones de trabajo" y microemprendimientos (panaderías, talleres de costura, etc.) para paliar la falta de empleo, se pusieron en funcionamiento ollas populares, huertas urbanas, guarderías para niños y hasta campañas de vacunación para los recolectores informales de reciclables (cartoneros). En otros casos, además se plantearon discusiones acerca del futuro político y económico del país organizándose en asambleas interbarriales y buscando establecer vínculos con los Centros de Gestión y Participación (CGP) —unidades administrativas descentralizadas del gobierno local.

Entender el surgimiento de las asambleas requiere hacer un recorrido por la Argentina post-dictadura y una democracia que, si bien se encontraba consolidada a casi veinte años de su retorno, hacía tiempo que había dejado de tentar a la participación política activa. El desencanto de muchos con el alfonsinismo, la sensación de arrasamiento y apatía generada durante el menemismo y el descrédito total hacia la clase política y hacia la política en general en los años de presidencia de De La Rúa, se sumaron a los efectos desmovilizantes de una prolongada dictadura que, hasta cierto punto, había logrado desarticular el tejido social y romper lazos de solidaridades.

Diciembre de 2001 fue una auténtica crisis orgánica o hegemónica, en el sentido gramsciano del término (Svampa, 2011; Gálvez, 2012; López y Ducid, 2016), es decir, un momento - y un espacio- en donde confluyeron contradicciones de larga data y de la cual surgió la posibilidad de algo completamente nuevo. En gran parte "la crisis" permite desandar esta trayectoria de escasa participación política e involucramiento con la realidad circundante. A la crisis política se sumaron las crisis económica, social y cultural estallando en las protestas de fines de 2001 que llevaron a la renuncia del presidente de la Nación y a una sensación generalizada de quiebre con el pasado reciente. Las movilizaciones casi diarias durante los meses de diciembre y enero congregaron a la gente en las calles, generaron nuevos espacios de discusión y fomentaron el encuentro.

A lo largo de los meses del verano 2001-2002 las asambleas se multiplicaron en diversas ciudades del país. Solo en CABA llegó a haber más de 100 asambleas (populares y vecinales). "La crisis", efectivamente, supuso una ruptura con las prácticas políticas pasadas y creó condiciones propicias para la emergencia de nuevos actores políticos. Uno de esos actores fueron, en su conjunto e individualmente, las asambleas populares y vecinales. Durante buena parte de 2002, las asambleas se mantuvieron activas, algunas en los espacios públicos en donde habían surgido, otras en locales ocupados, prestados o alquilados. Si bien para finales de 2003, casi todas las asambleas habían desaparecido como tales, algunas otras adquirieron otros formatos y funciones - por ejemplo, pasando a ser centros culturales comunitarios-. En algunos casos, no menos significativos por ser pocos, las

3 Cfr. el artículo en La Nación del 25 de marzo de 2002: "Nacieron 272 asambleas luego de los cacerolazos," (http:// www.lanacion.com.ar/383503-nacieron272-asambleas-luego-de-los- cacerolazos). 
asambleas se constituyeron en actores de referencia importantes en sus respectivos barrios con una presencia sostenida en el tiempo. Este es el caso de la Asamblea Popular Plaza Dorrego-San Telmo de la cual nos ocuparemos en este artículo.

El fenómeno asambleario fue abordado desde distintas perspectivas a lo largo de los años (Bielsa, 2002; Dinerstein, 2003; Rossi, 2005; Svampa y Corral 2006; Fernández, 2006; Pousadela, 2011). Según lo vieron algunos contemporáneos, este fenómeno significó la recuperación de la política, el debate y la posibilidad de acción para la sociedad civil por fuera de la política tradicional ante lo que se veía como el fracaso de la democracia representativa (Bonasso, 2002). Las asambleas representaron una inversión del "sálvese quien pueda" y del individualismo neoliberal instalado en la dictadura y consolidado durante los años noventa que se asoció fuertemente con la recuperación del sentido de ciudadanía, del bien común y de la solidaridad (Bielsa, 2002). Para Barbetta y Bidaseca (2004) el 19 y 20 de diciembre se presentó como acontecimiento que dio lugar al renacimiento de la política. Así, la clase media, mediante su participación en las asambleas, se convierte en protagonista y recupera la política para sí.

Rossi (2005), por su parte, se interesó en las condiciones de emergencia y eventual ocaso del movimiento asambleario. Este autor afirma que fue la respuesta tardía de las elites políticas a la pueblada de diciembre 2001 y la puesta en suspenso de la institucionalidad lo que les permite a las asambleas movilizar un discurso de impugnación de lo instituido - "ique se vayan todos!"- y convertirse en un importante actor político con poder para incidir en la salida a la crisis de representatividad. Sin embargo, dadas las contradicciones en su interior, no encontró modo de preservarse frente al retorno de la institucionalidad agotando así su relevancia política. Por su parte, el trabajo de Ouviña (2008) hace foco en la dimensión organizativa de las asambleas y destaca la potencialidad inherente en la tensión entre democracia directa y representación de la dinámica asamblearia. La organización horizontal significa hacer de esta contradicción el motor para la creación de algo nuevo. La dinámica asamblearia es así prefigurativa (Ouviña, 2009), dado que el hacer aquí y ahora es parte del objetivo y no solo un medio para llegar a él en algún futuro más o menos lejano.

El interés por el estudio de las asambleas decreció con posterioridad al 2005/2006. Para esta altura, la movilización había decaído mucho y la vida política había retornado a sus canales institucionales formales habituales. Según algunos autores, el gobierno de Kirchner (elegido en 2003) puso en práctica estrategias de cooptación de los movimientos sociales mediante la incorporación de gran parte de sus reclamos y dirigentes a la gestión (Rajland y Campione, 2006; Svampa, 2008). Otros, han enfatizado las diversas lógicas de construcción socio-histórica de los movimientos sociales en Argentina para comprender esas vinculaciones, tensiones y cooperaciones sin quitarle capacidad de agencia a las organizaciones (Retamozo, 2011; Natalucci, 2011). En este contexto, muchas asambleas ya se habían disuelto o estaban en proceso de hacerlo perdiendo visibilidad y aparente relevancia.

Sin embargo, consideramos que el desinterés en las asambleas como fenómeno político no solo responde a una mirada sesgada sobre lo que es políticamente relevante, sino que además obtura la posibilidad de nuevas lecturas que a su vez echen luz sobre la política urbana. En efecto, un análisis de aquellas asambleas que llegaron a conformarse como referentes barriales permite entender la importancia que las mismas 
tienen dentro del conglomerado de organizaciones de base y en lo que respecta a la política vinculada a problemas sociales en el ámbito local (Di Iorio y Farías, 2020). Además, las asambleas se constituyen y funcionan como importantes espacios de encuentro desde los cuales, mediante el trabajo colectivo y horizontal, se dan las condiciones para la transformación subjetiva y para la generación de propuestas que contienen una potencia política radical (Farías, 2016; 2018).

En este sentido, en este artículo nos proponemos mirar el caso específico de una asamblea popular para dar cuenta de los modos en los que desde su accionar, estas organizaciones no solo plantean demandas vinculadas a la exigibilidad de derechos, sino que además proponen otros modos de pensar la ciudadanía y el acceso al espacio urbano y su uso. Queremos resaltar la importancia que tiene la AST -y por extensión todas las asambleas vigentes- para reflexionar sobre la construcción de ciudadanía en tiempos en donde se profundizan las desigualdades sociales y en donde se pone en entredicho su carácter universal. En pos de este objetivo, a continuación, señalaremos algunas referencias teóricas con las cuáles nos interesa dialogar.

\section{Herramientas teóricas y metodológicas}

El interés de los estudios antes reseñados se ubicó en dimensiones que ligan con el propósito de este trabajo, como la dimensión organizativa y el análisis de la recreación de espacios de sociabilidad política alternativos a la representación liberal. Sin embargo, ninguno de ellos ha vinculado estas experiencias con la definición y propuesta urbana que suponen. Bajo este horizonte, consideramos que la idea de ciudadanía urbana puede tener un amplio potencial para comprender algunos de los rasgos del fenómeno asambleario.

Para comenzar a delinear el complejo tema de la ciudadanía, nos remitimos primero a la perspectiva de Chatterjee (2006), autor que enfatiza la transformación en la concepción de política democrática que se da entre el siglo xx y la actualidad, pasando de un concepto de democracia basada en la idea de soberanía popular a uno en el que la política democrática se configura por la gubernamentalidad. Esta mutación tiene estrecha relación con la tensión entre, por un lado, el ideal universal propio del nacionalismo cívico, basado en las libertades individuales y la igualdad de derechos y, por otro, la emergencia de las ciudadanías diferenciadas. Estas emanan de las crecientes demandas de diversas identidades culturales, que exigen el tratamiento diferenciado de grupos particulares por motivos de vulnerabilidad o injusticias históricas. Chatterjee resalta que el espacio real de la vida moderna consiste en la heterotopía, el tiempo es heterogéneo y la política no significa lo mismo para todos. Ejemplos de prácticas y sentidos que podrían considerarse "premodernos", en realidad configuran diversos encuentros con la modernidad y, por ende, no deben pensarse como "residuos" a ser superados, sino como elementos necesarios para comprender los heterogéneos tiempos de la gubernamentalidad.

Dicha heterogeneidad de tiempos y conceptos de la política puede, entonces, vincularse a espacios heterogéneos, entre los cuales es específicamente el espacio urbano el que nos interesa resaltar. Podemos retomar, en este sentido, a Holston (2009) quien identifica la posibilidad de que emerjan nuevas formulaciones de ciudadanía para su movilización basadas en la residencia urbana. Dichos movimientos se focalizan 
en la desigualdad de las condiciones urbanas para la definición de su agenda de reclamo de derechos y prácticas participativas. Estas prácticas y sentidos se articulan a una visión colectiva y comunitaria de la vida urbana que, por supuesto, colisiona con los imaginarios en torno a la ciudad construidos desde ciertos sentidos comunes: anonimato, individualismo, interacciones sociales efímeras y caóticas, etc. La propuesta del autor en torno a pensar en lo que llama "enredos" de ciudadanía es sugestiva, puesto que atiende al surgimiento de nuevos tipos de ciudadanos urbanos que amplían la ciudadanía democrática y, también, nuevas formas de violencia urbana y de desigualdad que la deterioran. Su análisis se centra en los movimientos surgidos en las periferias urbanas.

En la misma línea y siguiendo estudios desde la teoría feminista que cuestionan las definiciones tradicionales y liberales de ciudadanía, Marston y Mtichell (2004) proponen el concepto de "citizenship formation". ${ }^{4}$ Este concepto se refiere a la ciudadanía como "una construcción no estática, no lineal, política, cultural económica y legal" que es modelada contextualmente (p. 95. Traducción propia). Para estas autoras la ciudadanía es algo siempre en formación, en desarrollo, que cambia según va modificándose la posición del Estado en el contexto de la economía global. Es decir, si bien el Estado es el marco de referencia para la definición de la ciudadanía y el interlocutor al cual se le reclama el acceso a la misma, la expansión o la contracción de esta (la ampliación de derechos, o por el contrario, su restricción) dependerá del rol de diversos actores en múltiples escalas, desde lo local a lo global. De este modo, la ciudadanía se torna un concepto elástico cuyo contenido no solo no es evidente, sino que tampoco puede tomarse como un dato dado.

Avanzar sobre la configuración de novedosas ciudadanías urbanas, presenta contenidos y formulaciones que tensionan las definiciones individualistas propias de la ciudadanía liberal. En este sentido, es preciso detenernos en dos conceptos claves que serán luego articulados en el análisis empírico: el espacio público y su disputa y, por otro lado, el derecho a la ciudad.

Respecto al concepto de espacio público, entendemos que es un concepto difícil de definir, que muchas veces se utiliza de modo descuidado e impreciso (Iveson, 1998). En un sentido intuitivo, el espacio público remite a espacios cuyo acceso es libre y opuesto a lo privado, es decir, al ámbito de lo doméstico. Desde una concepción habermasiana, el espacio público se convierte en un espacio de encuentro con ciertas reglas que regulan el intercambio entre personas supuestamente iguales (o igualadas) que conforman la ciudadanía. Esta apreciación liberal - y más generalizada - del espacio público, supone un "público" que tendría un acceso irrestricto, tanto a dicho espacio como a los bienes y/o servicios que en el mismo se provee. Aún siendo este el caso, las preguntas que surgen inmediatamente tienen que ver con quién establece las reglas de funcionamiento del espacio público (qué se puede hacer y cómo) y quién es el público que lo puede habitar.

Las concepciones idealizadoras del espacio público como ámbito de igualación y de libre acceso han sido criticadas por diversos autores que encuentran que no solo es difícil definir al espacio público (Gorelik, 2008), sino que además al hacerlo se corre el riesgo de cosificarlo y asumirlo como un espacio contenedor neutral y objetivo (Estévez Villarino, 2012). Al mismo tiempo, la dicotomía espacio público-espacio privado como organizadora de la vida política ha sido ampliamente
4 Traducido aproximadamente como "formación de ciudadanía". Remite a las formaciones geológicas siempre en movimiento y cambiantes. 
cuestionada por las teorías feministas. Dichas teorías han resaltado el solapamiento de ámbitos (público/privado, político/no-político), que permite pensar al espacio público en términos de práctica, proceso, posibilidad, acontecimiento, lo que hace menos evidente qué es el espacio público y quiénes son los sujetos portadores de ciudadanía (ver, por ejemplo, Bondi, 1998; Domosh, 1998; Marston y Mitchell, 2004). Definir al espacio público y al público que accede al mismo son procesos simultáneos que no son siempre evidentes y que conllevan exclusiones. En este sentido, si el espacio público se muestra como transparente es porque los usos posibles ya se encuentran definidos y, esa supuesta transparencia y orden neutral oculta, de hecho, las disputas de poder que configuran dicho orden. Las heterogéneas maneras de habitar el espacio público, tal como más adelante desarrollaremos de la mano de Motta, Martín y García (2013) a través del caso de las personas en situación de calle, permiten visibilizar dichas tensiones y disputas.

Es notable cómo el debate en torno al espacio público y el derecho a la ciudad se liga con las modalidades y formas de comprender y ejercitar la ciudadanía. En este trabajo nos interesa indagar sobre propuestas de ciudadanía que divergen de la ciudadanía hegemónica liberal. Para ello, nos centraremos en las formas de ciudadanía urbana que se recrean en el caso de la AST, que no surgen de la experiencia de la periferización física, sino más bien simbólica. Los procesos de desigualdad, violencia y discriminación contra los cuales militan los miembros de la AST, transcurren en un barrio que posee centralidad en CABA. Pero, a pesar de dicha centralidad, los sujetos protagonistas, no dejan de reconocerse excluidos de las formulaciones hegemónicas sobre la ciudadanía (de definición formal universal y ejercicio individualista de los derechos), y batallan por reconfigurar las prácticas y sentidos de lo que implica vivir en el barrio, participar de la ciudad y definir los usos posibles de los servicios, el espacio público y el barrio.

Se presenta un estudio de caso sobre la AST, bajo una modalidad de investigación descriptiva e interpretativa, que tiene como objeto central la descripción de los fenómenos a partir del acercamiento a la realidad en un periodo dado. Para ello se propone una aproximación metodológica cualitativa que abreva en diferentes métodos de construcción de datos, basándonos en una muestra y saturación teórica. A raíz de un período de investigación desarrollado durante 2013 y 2014, y con seguimientos posteriores, realizamos observación participante y no participante en diferentes acciones y prácticas de la organización (laborales, educativas, de salud, culturales, asistenciales, políticas, organizativas) en diferentes contextos de acción cotidianos en el local de la AST y durante acciones extraordinarias como asambleas, espacios de interacción con otros colectivos en el barrio y movilizaciones. Realizamos entrevistas en profundidad - un total de 15 grabadas-y varias conversaciones informales con diversos miembros de la organización. También se apeló al relevamiento de fuentes secundarias, como periódicos nacionales y material elaborado por la propia organización.

\section{Asamblea Popular Plaza Dorrego-San Telmo}

La AST surge en el barrio de San Telmo en la plaza que lleva su nombre (ver Figura 1) en los días que siguieron a la rebelión del 19 y 20 de diciembre de 2001. Militantes de la coordinadora Encuentro, Memoria, 
Verdad y Justicia ${ }^{5}$ tuvieron mucho que ver con el impulso inicial de la Asamblea, pero su composición era de todos modos muy heterogénea, con gente con y sin militancia previa. Como tantas otras asambleas, inmediatamente se organizó en comisiones encargadas de llevar adelante las distintas líneas de acción, como la de "Desocupados", "Huerta", "Derechos Humanos y Cultura", "Trabajo", "Educación”, "Prensa y Comunicación", "Salud", "Finanzas" y también "Construcción" (esta última surge cuando hacia fines de 2002 se ocupa un lote vacío, se obtiene un permiso para su uso y se decide construir un local de dos pisos en el que la Asamblea continúa funcionando). Las comisiones fueron cambiando según las transformaciones del contexto y en la medida en que surgían prioridades y necesidades de acción. Así, hoy en día las comisiones son "Derechos Humanos", "Olla (por olla popular)", "Cultura" y "Hábitat".

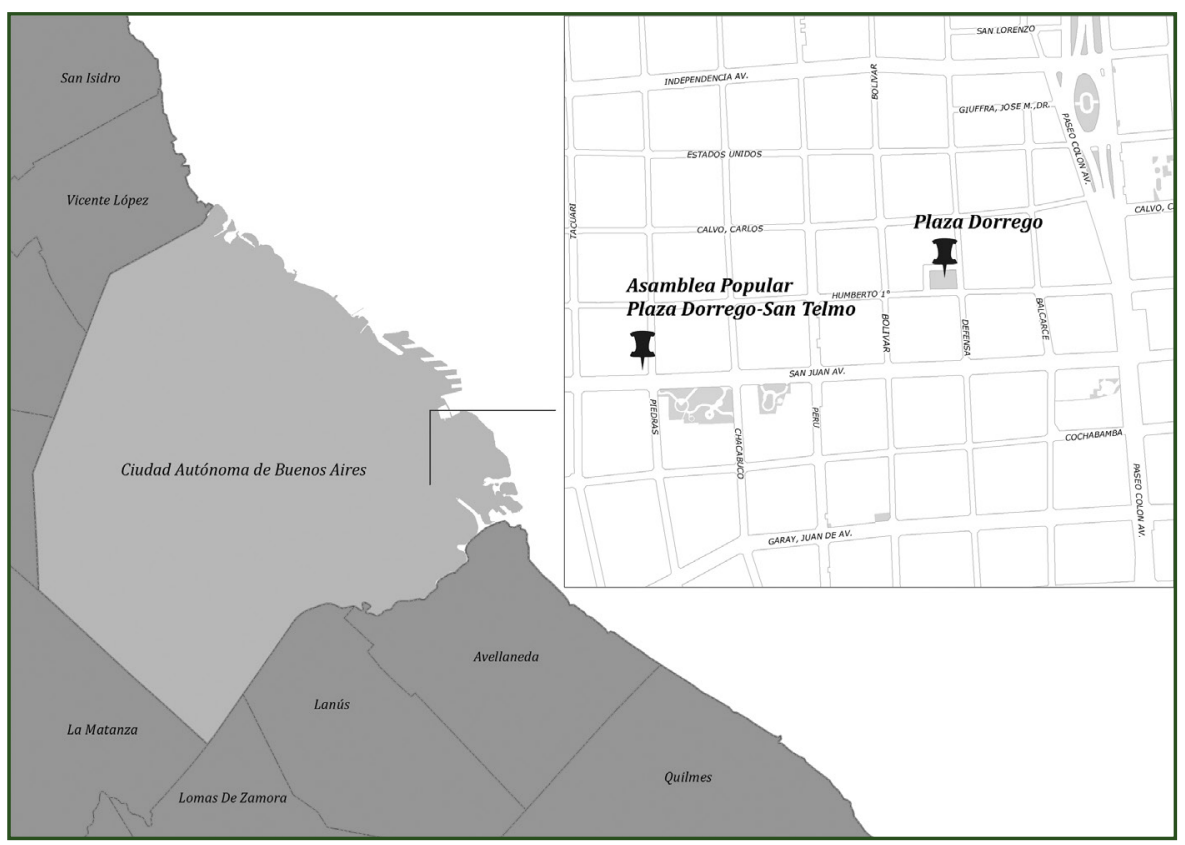

Una de las características más salientes de la AST ha sido (y es) la de comprometerse con las cuestiones más apremiantes del barrio, participando activamente de las disputas que se dan en él. Para ello, considera fundamental la articulación con otros actores barriales, así como con actores por fuera del barrio y a escala de la ciudad. La AST se define como,

una organización barrial-social autónoma, con origen y contenido político (pero no adscripta a ningún partido) [...], es una organización territorial que prioriza su trabajo en función de las necesidades del barrio. Basada en principios de solidaridad social y defensa de derechos humanos [que] desarrolla una experiencia organizativa de participación pluralista, democrática y autónoma con funcionamiento asambleario y horizontal (Tríptico informativo, 2018. Resaltado en el original).

La AST participó del proceso de recuperación del Ex Centro Clandestino de Detención, Tortura y Exterminio "El Atlético" localizado a pocas cuadras del local de la asamblea bajo el terraplén de la autopista Ricardo Balbín 25 de Mayo en la Avenida Paseo Colón y Cochabamba. Como parte de la Coordinadora de Barrios por la Memoria, además,
Figura 1. Ubicación de la Asamblea Popular Plaza Dorrego-San Telmo y de la Plaza Dorrego Imapa elaborado para este artículo por la Lic. Fernanda Zaccaria)
5 Se trata de una coordinadora de organizaciones de derechos humanos que surge en 1996 para llevar adelante la organización de la marcha del 24 de marzo a 20 años del golpe cívico-eclesiástico-militar de 1976. Desde entonces, Encuentro por la Memoria ha participado en las causas por violaciones a los derechos humanos durante ese período además de numerosas disputas vinculadas a la violencia estatal en democracia. 
ha venido ocupándose de la colocación y mantenimiento de las baldosas de la memoria que recuerdan a los detenidos-desaparecidos del barrio. Así mismo, todos los años, el fin de semana previo al 24 de marzo, la AST convoca a otras organizaciones del barrio a realizar la Marcha de Antorchas que se inicia en el local de la AST y concluye en el ex CCDTE "El Atlético", luego de haber pasado por algunas de las baldosas del barrio. Según lo expresara el documento leído en la marcha de 2019, cada Marcha de Antorchas es,

[u]n intento de recuperar la vida y los modos de sentir y de pensar de eses compañeres desde lo singular y lo colectivo, reivindicado sus luchas y sus militancias. Es una manera de resignificar la memoria social y barrial, de comprender el pasado problematizando el presente. Este recorrido [...] es homenaje y es reivindicación. Caminando recuperamos y resignificamos un espacio público en el que también se expresa un proyecto de expulsión, exclusión y miseria (Documento Marcha de Antorchas, 2019. Resaltado en el original).

En este mismo sentido de recuperación del espacio público, la AST participa de numerosos reclamos por su preservación y contra las limitaciones a su acceso, como fueron las protestas en contra del enrejamiento del Parque Lezama en 2013 y 2014. También se involucra en las disputas por otorgarle nuevos sentidos que expresen deseos y propuestas colectivas de arte popular, como cuando defendió el Mural de la Memoria en donde hoy se encuentra el Museo de Arte Moderno que sintetizaba las luchas desde 1976 hasta el 2001, o reclamaron contra la destrucción del mural a los caídos en la Masacre de Trelew en una plazoleta del barrio. Además, a través de su participación en la Mesa de Salud y Educación del barrio, que reúne a diversos actores en torno al Centro de Salud y Acción Comunitaria del barrio, busca garantizar el acceso integral a la salud por parte de los habitantes del barrio y lograr obtener un edificio nuevo y más recursos para su apropiado funcionamiento.

Desde el grupo de género que integra la AST, vienen participando de luchas vinculadas al movimiento trans-feminista, sobre todo desde las movilizaciones de Ni Una Menos en 2016. Participa de los Encuentros Plurinacionales de Mujeres, Lesbianas, Travestis, Trans y No Binaries que se realizan anualmente y articula con otros colectivos de mujeres y diversidades realizando intervenciones en el barrio - como asambleas en las plazas, pegada de carteles con consignas, etc.

En cuanto a los temas de vivienda, quizás la disputa más emblemática de la que la AST tomó parte fue la del ex Padelai (Patronato de la Infancia), convertido en caso paradigmático de avance de las políticas de renovación urbana con fines de especulación inmobiliaria. Ocupado por primera vez en 1984, es desalojado definitivamente en 2017 luego de un largo proceso que incluyó desalojos previos, negociaciones con el gobierno local y la intervención de la justicia. La importancia de este caso radica también en lo que Carman y Yacovino (2007) denominan un "desalojo ejemplar" por el despliegue represivo con el que se llevó a cabo el desalojo del 2003 con la finalidad de desincentivar otras resistencias. Junto con otras organizaciones, que también tomaron parte en dicha disputa, la AST conforma el Colectivo de Organizaciones de Hábitat, integrado además por numerosas cooperativas (tanto a nivel local como nacional) que promueve la nacionalización de la Ley 341/2000 de construcción colectiva y autogestionaria del hábitat. 
Otra de las actividades estructurantes, y quizás la más visible de la AST, es la olla popular (comedor popular) que se lleva a cabo todos los domingos. "La Olla" es tan antigua como la AST y, según lo definió uno de sus integrantes a una de las autoras, es "como una ventana al barrio" (Entrevista con G., participante de la AST, 14/02/14). Si bien la Olla no funcionó siempre de la misma manera — en cuanto a la dinámica y los criterios de trabajo - desde hace ya muchos años funciona para, por y con PSC con un enfoque que la distingue de otras ollas populares, ya sea que funcionen en iglesias, ONGs u otras organizaciones barriales. Contrariamente a muchos comedores barriales (algunos en iglesias) y ONGs que poseen una mirada asistencialista hacia las PSC que promueve su pasividad, la AST despliega estrategias de intervención que alientan su autonomía. Se parte del reconocimiento de los condicionantes estructurales que (re)producen la situación de calle, pero en la cual las PSC como sujetos de derecho, deseantes y autónomos, construyen y modifican su realidad. De hecho, otro militante de la AST desde sus orígenes, comenta que la idea no fue nunca "dar solo el plato de comida" (L., participante de la AST, 06/13/14). Los miembros de la AST hablan de la Olla como un lugar en donde se cocinan muchos guisos, en clara alusión a la diversidad de necesidades a las cuales se atiende en ella.

La Olla funciona los domingos desde las nueve de la mañana cuando comienzan las actividades, se sirve el desayuno, se arma el salón con tablones y sillas y se prepara el guiso que se servirá al mediodía hasta aproximadamente las $16 \mathrm{~h}$, cuando se termina con la limpieza del salón y se desarrolla la reunión de balance posterior a la actividad. Mientras tanto, diversas actividades ocupan el salón donde la gente lee el diario, conversa o dormita sobre la mesa. Dependiendo del domingo, las actividades varían entre un taller de escritura, un grupo de escucha, un programa de radio y un espacio para manifestarse por medio de diversas expresiones artísticas. Algunos domingos, luego del almuerzo, se llevan a cabo salidas "turísticas" por distintos barrios de la ciudad, organizadas por un equipo de la AST del cual participan personas que asisten a la Olla. ${ }^{6}$

Con relación a la problemática de calle, hace ya muchos años que la AST se constituyó en la ciudad como un actor importante en la materia. En el año 2010 fue el sitio de encuentro para las discusiones que derivaron en la Ley 3706/2011 de la CABA de "Protección y garantía integral de los derechos de las personas en situación de calle y en riesgo a la situación de calle". Desde entonces, viene participando de numerosas instancias de intercambio con otras organizaciones y con ámbitos legislativos para pensar y actuar sobre la problemática. En 2017 y 2019, ante la inacción del gobierno local para la obtención de datos precisos sobre la cantidad de personas viviendo en la calle, la AST participó de la organización y realización del Censo Popular de Personas en Situación de Calle que durante cuatro días movilizó a cientos de voluntarios en toda la ciudad.

\section{Redefiniciones de la ciudadanía desde las prácticas de la Asamblea}

\section{La problemática de estar en situación de calle: visibilización y ciudadanización}

Desde el año 1999 el gobierno de la Ciudad de Buenos Aires lleva a cabo conteos anuales de las personas viviendo en la calle. Desde entonces y hasta 2019, según estos conteos, el número de personas en situa-
$6 \quad \mathrm{Al}$ menos este era el funcionamiento previo a la declaración de la emergencia sanitaria a raíz de la pandemia de COVID-19.

7 Este es la denominación utilizada en la Ley 3.706 que define a las personas en situación de calle como "los hombres o mujeres adultos/as o grupo familiar, sin distinción de género u origen que habiten en la calle o espacios públicos de la Ciudad Autónoma de Buenos Aires en forma transitoria o permanente y/o que utilicen o no la red de alojamiento nocturno". 


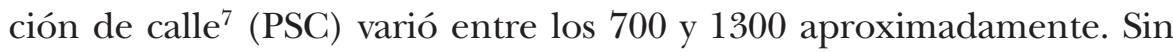
embargo, las organizaciones sociales y las ONG que, de un modo u otro, se ocupan de las PSC afirman que la problemática ha empeorado a lo largo de los años, siendo el número mucho mayor al propuesto por el gobierno. El dato más preciso y reciente con el que se cuenta es el del Segundo Censo Popular de Personas en Situación de Calle (CPPSC) realizado en abril de 2019 por un conglomerado de organizaciones sociales que contó 7251 PSC. Es de esperar que este número haya crecido a raíz de la pandemia de COVID-19 que afectó gravemente a los circuitos de la economía informal de los que depende una gran parte de los habitantes en situación de riesgo habitacional. De las 15 comunas en las que se divide la ciudad, la Comuna 1, integrada por los barrios de San Telmo, Retiro, Monserrat, Constitución, Puerto Madero, y en donde se encuentra la AST, ha sido históricamente la comuna con mayor porcentaje de PSC de la ciudad. Según el primer CPPSC realizado en 2017, ese porcentaje era de $28 \%$. Si bien no hay datos desagregados por comunas para los años anteriores, se estima que el porcentaje es similar y en este sentido, abordar esta problemática era casi inevitable para la organización.

La AST entiende que el problema de la situación de calle no responde al orden de lo individual, si bien se reconoce que algunas personas atraviesan situaciones particulares que las dejan en condiciones de vulnerabilidad, potenciando así el riesgo a estar en situación de calle - problemas de salud mental, de consumo, familiares, etc.- Esta es una de las razones por la cual la Olla de la AST se distingue de otras ollas o comedores populares que, haciendo foco en el sujeto y su carencia, funcionan con una lógica asistencialista. G. reflexiona sobre el trabajo de la organización y dice,

[S]i la olla fuera un lugar así, con esa... [forma] miserabilista (risas) de mirar, objetivar al otro como una "bueno $[\ldots]$ dale la polenta a este chabón y qué bueno que soy”, yo o la combatiría o [...] igualmente yo pienso, que el objetivo de las ollas son que no existan más ollas (sonrisa) que no haya ollas, no tiene que haber ollas, entonces el objetivo político es luchar contra condiciones que generan que haya gente que tiene que ir a comer ahí (entrevista con G., participante de la AST, 14/02/14).

En el mismo sentido, J. cuenta que en la AST y en la Olla,

La comida como una manera de construir poder con el otro. Digo, cuando yo al ciruja que está todo roñoso le digo "andá a lavarte las manos y vení y cortá las papas" ¿sí? Viste que cuando ponés el guiso en la olla y está diciendo "uy qué rico que está", te lo están diciendo a vos ¿entendés?, porque vos lo hiciste porque entonces vos no sos un ser desechable en una sociedad que produce desechos humanos porque eso es, digo, es el desecho, es [...] la persona con la que nosotros laburamos es el desecho social, ¿entendés? ¡Ni siquiera el ejército de reserva! Es el exceso de la sociedad capitalista, entonces, yo no lo estoy mirando como desecho ahí, yo estoy diciendo en la medida que esa persona participa, se transforma a sí mismo y transforma el colectivo (entrevista con J., participante de la AST, 04/02/14).

El giro en materia de gobernanza urbana, de una ciudad que pueda satisfacer las necesidades de reproducción de sus habitantes a una ciudad orientada para el mercado, ha generado dinámicas socioespaciales contradictorias, tensiones que producen procesos de exclusión en la ciudad (Girola, Yacovino y Laborde, 2011). Las políticas de re- 
conversión y recuperación urbana están acompañadas por una retórica meritocrática que deposita en los individuos la sola responsabilidad de sus éxitos y sus fracasos, medidos por lo general en términos económicos (Mitchell, 2003). En este orden urbano comodificado, el habitante de la calle, carente de recursos materiales mediante los cuales acceder a la ciudad, no encuentra - no tiene- lugar. Los militantes de la AST tienen una comprensión de las desigualdades en la ciudad que enraízan en miradas relacionales del espacio y que confrontan con las concepciones que ven a la ciudad como algo que se compra, vende y consume. En este sentido, E. comenta sobre el estereotipo de que en las villas (asentamientos precarios en la ciudad) "son todos vagos" y se pregunta,

Y la señora que te lava tu casa ¿dónde poronga vive? El albañil que hizo esta casa ¿dónde estaría viviendo? ¿en Nordelta? Porque (risas) [...] es como la parte fea y es como bueno, nos gusta Puerto Madero y lo que hay que sacar es la villa sin entender que la misma sociedad es la que genera Puerto Madero y la villa, tiene que cambiar la sociedad para que cambien los dos extremos, no es que decís bueno, sostengo esto que está lindo y barro lo otro, viene todo el paquete junto, si no te gusta una parte del paquete hay que desarmar el paquete, eso me parece que cambia mucho (entrevista con E., participante de la AST, 07/07/14).

La problemática de calle es vista como el resultado de fenómenos de exclusión y marginación generados, en un contexto de acumulación de capital, vía mercado inmobiliario, aunque claramente no reducido solo a este. Se entiende que este tema se inserta en un complejo escenario conformado por vínculos sociales y familiares, condiciones laborales, económicas y de salud, pero que resulta fundamental abordarlo como un tema de accesibilidad a derechos. Esto es particularmente evidente en el trabajo concreto que hace la Olla que la distingue de espacios de asistencia a las PSC.

La modalidad de trabajo de la Olla se caracteriza porque las mismas PSC son quienes cocinan. Los domingos, militantes de la AST abren el local y coordinan las actividades, pero en la cocina y armando el salón donde la gente desayuna y almuerza - y en donde se llevan a cabo actividades diversas- hay varios compañeros en situación de calle, que van rotando de semana a semana. La intención detrás de esta forma de trabajo la explica J.,

Yo creo que esa mirada de que el plato es una excusa, que lo que queremos es otro vínculo con la persona, reconocerla como sujeto de derecho, eso lo compartimos todos, eso [...] y desde que surgió la olla porque fijate que los que cocinan son los compañeros, a veces con mayor nivel de participación, a veces menos. Tratamos que el jueves de que se sumen [a un grupo de escucha que se estaba armando en ese momento], capaz se suma uno, no importa, pero que se sienta que puede venir a cualquier otra actividad. Vos los ves, vienen a la peña, vienen un jueves, no vienen solo a cocinar a la olla, entonces ¿vienen por la comida? No. Vienen por otra cosa, por las necesidades afectivas (entrevista con J., participante de la AST, $04 / 02 / 14)$.

La AST entiende a la problemática de situación de calle como algo que entra en el orden de la ciudadanía, para el cual el Estado debe dar respuestas. Pero para generar las herramientas de intervención estatal 
apropiadas, el problema, en primera instancia, debe ser reconocido. Una de las cosas que la AST denuncia con más insistencia es, justamente, la invisibilización, el ocultamiento de esta problemática por parte del gobierno local. Mencionamos previamente que las estimaciones del número de PSC por parte de las organizaciones sociales y las ONGs son mucho mayores que las del GCBA. La negación del número "real" de PSC es una forma de ocultamiento e invisibilización que resulta en su exclusión del orden de lo público, aunque, paradójicamente, su cotidianidad se desarrolle precisamente en el espacio público y a la vista de todos. La ausencia de políticas públicas integrales y la ineficiencia de los programas y las pocas políticas existentes hablan de la PSC como sujeto que no es contemplado cuando se piensa la política pública.

Las actividades que se llevan a cabo en la AST que más directamente tratan con PSC, particularmente aquellas vinculadas a la Olla, son pensadas sobre la necesidad de afirmar que las PSC son "sujetos de derechos". Por ejemplo, los recorridos turísticos que se arman por distintos barrios por, para y con las PSC — que revelan en sus recorridos historias no contadas de la ciudad-son una expresión del derecho a la recreación y al paseo. Las actividades artísticas que a veces se llevan a cabo durante la espera para comer — karaoke, armados de collages colectivos, música grabada o en vivo- reclaman para las PSC el derecho al arte, a disfrutarlo y por sobre todo, a hacerlo. El taller de escritura y el espacio de escucha previos al almuerzo afirman el derecho a decir, a tener voz, y a ser escuchado. Del mismo modo, abrir las puertas de la AST para que las PSC pasen la mañana, disfruten de actividades, protegidas de la lluvia o el frío y se sienten a comer, recrea una suerte de comida familiar de domingo y reafirma el derecho a compartir la mesa.

Intelectuales feministas y poscoloniales resaltan el carácter funcional de las exclusiones para reproducir la coherencia interna de los proyectos dominantes - ya sea el colonialismo, el (neo) liberalismo o la modernidad- (Gregory 1995; Mitchell, Marston y Katz, 2003) y la identificación de un "otro interno significativo" dentro del territorio nacional cuya presencia se torna fundamental para la construcción de un ideal nacional (Triandafyllidou 1998). Esta exclusión simbólica y discursiva - dado que rara vez estos sujetos forman parte de los relatos oficiales- se plasma en exclusiones materiales de hecho. Esto es lo que Holston denomina "ciudadanía inclusivamente desigual", en donde un sistema de ciudadanía diferenciada garantiza inclusión universal en teoría, pero establece límites tangibles para su acceso (Holston 2009). Creemos que la propuesta de la AST, relacionada a hacer visibles y a reafirmar derechos de las PSC, confronta con una idea de ciudadanía urbana sustentada en la reproducción de desigualdades y exclusiones.

\section{El hábitat urbano y el derecho a la ciudad: ¿una ciudadanía de derechos colectivos?}

La AST funciona en un local construido mediante donaciones y aportes personales en un remanente del ensanche de la Avenida San Juan vacante desde fines de los setenta que se ocupó a principios de 2002. ${ }^{8}$ Si bien el local se utiliza prioritariamente para las actividades de la AST, está abierto a otros grupos del barrio que carecen de un espacio para llevar a cabo sus tareas. Así, han pasado por la AST grupos candombe y de murga, de enseñanza popular, de acompañamiento educativo, talleres de folclore, de esténcil, de programación a través

8 Desde el 2002 hasta el 2009 la AST contó con un permiso de uso precario. En 2009 la Ley 2934 le garantizó el uso del predio por un plazo de cuatro años y en 2013 la Ley 4746 lo extendió por otros veinte. del juego, etc. Se han desarrollado ciclos de cine/debate impulsados 
por otros grupos militantes, peñas folclóricas, presentaciones de libros y charlas de diverso tipo. En el local de la AST también se suelen llevar a cabo reuniones de la Mesa de Memoria y del Comité Solidario entre otras instancias que articulan a los actores del barrio.

La construcción colectiva y comunitaria del local es indicativa de la concepción que la organización tiene sobre el modo de habitar el espacio urbano al tiempo que orienta las acciones y las prácticas que la sostienen. Por ejemplo, con relación a cómo se sustenta la olla popular una participante de la AST comenta acerca de la decisión política de no recibir aportes del Estado,

[...] no solo por la contraprestación que implica tener un comedor comunitario del gobierno de la ciudad, si no porque [...] o sea, es hacerse cargo, la idea para mí es que lo que no puede resolver uno individualmente, hay que resolverlo colectivamente, o sea, si un tipo solo no puede conseguir para comer bueno, entre todos cocinemos, pero no solo "entre todos cocinemos", loco ique el barrio también se haga cargo que hay gente del barrio o de la ciudad que no tiene para comer! y qque aporte! Digamos, es resolver colectivamente una necesidad individual. Eso es para mi la clave y por eso también la decisión de que las donaciones también haya que patearlas en el barrio por ejemplo (entrevista con Y., participante de la AST, 30/11/13).

En la respuesta colectiva a la falta de alimento de algunos vecinos del barrio se vislumbra una concepción de los derechos que, lejos de negar la responsabilidad del Estado de garantizarlos, destaca la cualidad colectiva de su ámbito de ejercicio. Es decir, el ejercicio pleno del derecho excede lo individual y pasa a ser parte de una dinámica más amplia que le da otro sentido. Es en este sentido que debe leerse la preparación colectiva de la comida de los domingos, en donde tanto los militantes de la AST como las personas que van a comer a la Olla, trabajan desde la mañana juntos cocinando, armando el salón y desarrollando actividades diversas dentro del mismo.

En otra entrevista una militante de la AST describió esta noción de lo colectivo como lo opuesto a los modos de construcción de la década del 90, años en los cuales se asienta el acuerdo neoliberal que establece la primacía de lo individual, la meritocracia y el acceso a los derechos vía el mercado,

esperá, una cosa te quería decir, la idea de que se construye colectivamente, porque por eso me acordé, por eso te dije algo de los noventa, porque los noventa nos mataron en ese sentido [...] en cuanto a lo cultural, ¿no? Bueno, ahora hay que pelear contra eso, contra esa construcción de los noventa, del individualismo, de toda la mierda esa. Engendrado a fines de los setenta, entonces si bien yo venía de la historia [...] ya desde una formación que ya a mi me permitía leer de otra manera [...] pero yo desde la asamblea, sabés que pude tener como una perspectiva mucho más amplia, es decir [...] ¿desde dónde miro? ¿viste? como, diagnosticar más cuál es el problema/es cultural (entrevista con M., participante de la AST, $13 / 02 / 14)$.

La crítica a ese individualismo adquiere otro sentido a través de la participación en la organización y de la pertenencia a un ámbito cuya lógica de funcionamiento prioriza lo colectivo por sobre lo individual. No niega ni anula lo individual, sino que adquiere otra dimensión al 
pasar a ser parte de una trama de relaciones. Es en esta clave en la que la AST piensa y lleva adelante las acciones en la ciudad.

La ciudad es un ámbito de reproducción y no solamente de producción y lucro y en este sentido, el derecho a la ciudad, concepto desarrollado previamente, solo se entiende en su lógica colectiva. Este es el sentido que subyace, por ejemplo, a la participación de la AST en la Mesa de Salud y Educación del barrio.

La Mesa (originalmente solo de salud) es una articulación entre distintos actores del barrio que nace en el 2017 a partir del último desalojo del ex Padelai para pensar usos posibles del edificio para el barrio. El objetivo principal consiste en utilizarlo para ampliar el Centro de Salud y Acción Comunitaria del barrio y para construir una escuela infantil. Esto no solo significa evitar la inclusión del edificio de casi 1500 metros cuadrados en el circuito inmobiliario, sino además utilizarlo para ampliar la accesibilidad al derecho a la salud y a la educación para los sectores más vulnerables del barrio.

La problemática de la situación de calle es un caso paradigmático para pensar las tensiones presentes en la búsqueda de ampliación de derechos en la ciudad. Las reacciones que provoca la problemática de calle en quienes no la habitan como vivienda son por lo general de dos tipos. Por un lado, la ausencia de registro de los cuerpos que duermen en los bancos de las plazas, en los cajeros automáticos, o en las puertas de los edificios como si las PSC fueran parte del paisaje urbano. De signo opuesto, la otra reacción se caracteriza por la indignación ante la presencia de un cuerpo que está donde no debería estar. En algunos casos puede que produzca enojo la precariedad y la inaccesibilidad a un derecho básico, pero lo que prevalece es la indignación que responde a la incomodidad ante la presencia de un cuerpo que según su percepción altera y afea el paisaje.

En última instancia, lo que estas reacciones tienen en común es la ausencia de interpelación al orden urbano. En un caso no se cuestiona lo que las PSC evidencian - la falta de una vivienda-y se naturaliza la desigualdad extrema, en el otro caso no se cuestiona la ausencia de una respuesta como sociedad al desamparo. En el orden urbano hegemónico, al cual se accede por vía del consumo, de la propiedad y de la conformidad a ciertas reglas sobre lo que se debe hacer y no se debe hacer en el espacio público, no hay lugar para las PSC. Ellas quedan por fuera de los debates que configuran dicho orden y, por ende, de sus normativas y sus políticas públicas.

En este punto es donde las acciones de la AST no solo interpelan a este orden urbano excluyente, sino que también proponen pensar las ciudadanías a partir de los derechos como algo colectivo. Con relación al primer punto, visibilizar la dimensión de la problemática de calle implica reconocer la dimensión del habitar del espacio público (Motta et al., 2013) y considerar lo que implica para su comprensión. La presencia de las PSC tensiona y cuestiona los supuestos habituales conferidos al espacio público, las interacciones que deberían darse y, por supuesto, el público (o los públicos) que en él se constituyen. En este sentido, la AST desarrolla numerosas actividades de visibilización. Por ejemplo, ha participado en las dos versiones del CPPSC, censos realizados por numerosas organizaciones sociales para confrontar con la minimización del problema por parte del GCBA. Según Di Iorio y Farías (2020), el Censo Popular se presenta como "un dispositivo de visibilización a partir de la datificación" que "visibiliza para humanizar y se datifica para incluir" (p. 227). Además, participa activamente de la Asamblea 
Popular por los Derechos de las Personas en Situación de Calle que desde 2019 lleva adelante campañas (presenciales y virtuales) para denunciar la violencia contra las PSC, entre otras actividades/instancias.

El segundo punto se evidencia en el hecho de que el comedor que funciona en el espacio de la AST no solo se ocupa de proveer alimentos para las personas en situación de calle, sino que además propone y desarrolla una serie de actividades culturales, artísticas y recreativas. Esas actividades no solo distinguen a la Olla popular de otros comedores de la red de asistencia para las PSC, sino que además propone la concreción de derechos que van más allá de la alimentación y que como este, también se resuelven colectivamente en un espacio precisamente construido de manera colectiva para usarlo de modo colectivo. En este sentido, si bien la AST plantea, exige y trabaja en pos del efectivo ejercicio del derecho a la vivienda, se entiende que vivir en la ciudad, el derecho a habitar la ciudad no se resuelve solo con el acceso a una casa.

Aceptar el acto de habitar la calle no significa normalizar esta realidad, sino tensionar la espacialidad urbana y las normas y sentidos comunes que regulan las acciones y los usos de los espacios en la ciudad. Si por espacio público entendemos aquel espacio en donde no acontece aquello que pertenece al ámbito de lo privado, entonces corresponde alguna de las dos reacciones que mencionamos más arriba. Pero si además de aceptar que los usos y regulaciones del espacio público no son uno y para siempre nos posicionamos en un enfoque de acceso a la ciudad desde la realización colectiva de los derechos, cambia el lente con el que miramos al espacio público y abandona su función normalizadora de la presencia de ciertos cuerpos (y no de otros). De este modo, se reafirma el derecho de las PSC a ser parte de la ciudad y a ser hacedores de la misma, y por lo tanto, hacedores de ciudadanía.

\section{Palabras finales}

Retomando las intenciones iniciales del presente trabajo, podemos argumentar que la experiencia de la AST configura intentos colectivos por generar desplazamientos hacia otros tipos de ejercicio ciudadanos y prácticas urbanas. Si bien el caso posee un alcance limitado y no puede plantear una clara alternativa a la ciudadanía individualizante, racional, eficiente y patrimonialista que impera en la mayoría de los actuales regímenes democráticos, consideramos que testimonia acerca de las tensiones y las potencialidades de estas.

Sobre las tensiones, reiteramos la centralidad de la relación entre lo público y lo privado que, si bien es un debate que tiene múltiples aristas que no hemos reconstruido en este trabajo, podemos mostrar la tensión que las prácticas de la AST suponen. Frente a políticas públicas que desconocen e invisibilizan y "limpian" el espacio público de ciertas problemáticas sociales, la asamblea, por el contrario, se empeña en mostrar, politizar y convertir en nuevos sentidos de ciudadanía, a través de prácticas concretas y cotidianas. Consideramos que los posicionamientos que toma la AST en torno a las problemáticas del hábitat urbano y, específicamente, a las personas en situación de calle, ofrecen un testimonio de que hay otras formas de atender estas problemáticas, tratar de encontrarles respuestas apostando a una ciudadanía realmente activa que trascienda los límites de los derechos considerados individualmente y los incorpore en un lenguaje desmercantilizador y colectivizante. Las PSC, entonces, no solo deben ser atendidas en sus 
urgencias materiales: comida, refugio, abrigo, sino que también deben ser contenidas afectivamente, humanizadas y fortalecidas. Para ello, es necesario cubrir sus urgencias, pero también volver a hacerlas protagonistas y usuarias de la ciudad. En este sentido, las diversas actividades que acompañan el acto específico de "dar comida", son, desde nuestro punto de vista, una de las propuestas más disruptivas y que invita a pensar, nuevamente, el sentido del derecho a la ciudad que excede por mucho al problema de la vivienda, que sin dudas es central, e involucra la posibilidad del goce, del acceso al arte, al ocio, y hasta, por qué no, de la belleza (Rodríguez y Zapata, 2020).

Consideramos, en fin, que algunos de los espacios de las asambleas barriales en CABA que, como fue analizado anteriormente, surgieron en un momento de crisis política y social del país muy particular, luego continuaron su accionar alrededor de temáticas específicas en torno al habitar la ciudad. En este trabajo nos propusimos recuperar estos ámbitos de organización que fueron objeto de amplio debate hace unos años, para reflexionar sobre lo que pueden decirnos sobre la producción y el ejercicio de ciudadanías. El caso que analizamos puede ser considerado una muestra elocuente de construcción de experiencias ciudadanas que poseen gran potencialidad para desplazar el corsé individualista con el que habitualmente se definen y se defienden los derechos ciudadanos, el espacio público y, en fin, el derecho a la ciudad. Sobre una plataforma de definición urbana, que tiene su raigambre en las asambleas barriales, se encuentran y se reconocen personas que buscan habitar de maneras más democráticas e inclusivas la ciudad, visibilizando lo invisibilizado, recuperando la memoria y el espacio público para poder construir de manera más cabal el tan mentado derecho a la ciudad. 


\section{Referencias bibliográficas}

Barbetta, Palbo y Bidaseca, Karina (2004). Reflexiones sobre el 19 y 20 de diciembre de 2001 "piquete y cacerola, la lucha es una sola": ¿emergencia discursiva o nueva subjetividad? Revista Argentina de Sociología, 2(2), 67-88. Recuperado el 5 de diciembre de 2021 de: https://biblat.unam.mx/hevila/Revistaargentinadesociologia/2004/vol2/no2/4.pdf.

Bielsa, Rafael A. (2002). Asambleas: ¿de la barbarie de la política a la civilización de los habitantes? En Bielsa, Rafael A. (Ed.), Qué son las Asambleas Populares (pp. 9-13). Buenos Aires: Ediciones Continente.

Bonasso, Miguel (2002). ¿Qué son las asambleas? En Bielsa, Rafael A. (ed.), Qué son las Asambleas Populares (pp. 14-21). Buenos Aires: Ediciones Continente.

Bonasso, Miguel (2002). ¿Qué son las asambleas? En Bielsa, Rafael A. (ed.), Qué son las Asambleas Populares (pp. 14-21). Buenos Aires: Ediciones Continente.

Bondi, Liz (1998). Gender, class, and urban space: Public and private space in contemporary urban landscapes. Urban geography, 19(2), 160-185. DOI: https://doi.org/10.2747/0272-3638.19.2.160.

Carman, María y Yacovino, María Paula (2007). "Transgrediendo el derecho de los que nos vulneran": Espacios ocupados y recuperados en la Ciudad de Buenos Aires. Revista Argentina de Sociología, 5(8), 26-48.

Chatterjee, Partha (2006). The Politics of the Governed: Reflections on Popular Politics in Most of the World. New York: Columbia University Press.

Dagnino, Evelina (2003). Citizenship in Latin America: an introduction. Latin American Perspectives, 30(2), 3-17.

Di Iorio, Jorgelina y Mónica Farías (2020). Problematizar las relaciones espacio-sujeto-situación de calle: el caso del Censo Popular en Buenos Aires, Argentina. Revista Colombiana de Sociología, 43(2), 215-237. Doi: https://doi.org/10.15446/rcs.v43n2.82807.

Dinerstein, Ana Cecilia (2003). "iQue Se Vayan Todos!": Popular Insurrection and the "“sambleas Barriales" in Argentina. Bulletin of Latin American Research, 22(2), 187-200.

Domosh, Mona (1998). Geography and gender: home, again? Progress in human geography, 22(2), 276-282. DOI: https://doi. org/10.1191/030913298676121192.

Donzelot, Jacques (2012). ¿Hacia una ciudadanía urbana? La ciudad y la igualdad de oportunidades. Buenos Aires: Nueva Visión.

Estévez Villarino, Brais (2012). La idea de espacio público en geografía humana. Hacia una conceptualización (crítica) contemporánea. Documents d’anàlisi geogràfica, 58(1), 137-163.

Farías, Mónica (2016). Working Across Class Differ- ence in Popular Assemblies in Buenos Aires. En Encountering the City: Urban Encounters from Accra to New York, Jonathan Darling y Helen F. Wilson, 169-186. Abingdon-New York: Routledge. DOI: 10.4324/9781315579467-10.

Farías, Mónica (2018). "Contesting Exclusion: Solidarity Spaces and Changing Political Subjectivities in Buenos Aires, Geoforum. DOI: https://doi. org/10.1016/j.geoforum.2018.05.001.

Fernández, Ana María (2006). Política y subjetividad: asambleas barriales y fábricas recuperadas. Buenos Aires: Tinta Limón Ediciones.

Gálvez, Eduardo (2012). Crisis y recomposición de la hegemonía tras el derrumbe de la Convertibilidad (1999-2003). Revista Perspectivas de Políticas Públicas, 2(3), 177-195. DOI: https://doi.org/10.18294/ rppp.2012.616.

Girola, María Florencia, María Paula Yacovino y Soledad Laborde (2011). Recentrando la centralidad: procesos de recualificación urbana y espacio público en la Ciudad de Buenos Aires desde una perspectiva etnográfica. Cuaderno Urbano. Espacio, Cultura, Sociedad,10(10), 25-40.

Gorelik, Adrián (2008). El romance del espacio público. Alteridades, 18(36), 33-45.

Gregory, Derek (1995). Imaginative geographies. Progress in Human Geography, 19(4), 447-485.

Holston, James (2009). La ciudadanía insurgente en una era de periferias urbanas globales. Un estudio sobre la innovación democrática, la violencia y la justicia en Brasil. En Delamata, Gabriela (Ed.), Movilizaciones sociales: ¿Nuevas ciudadanias? (pp. 45-65). Buenos Aires: Biblos.

Iveson, Kurt. 1998. Putting the public back into public space. Urban Policy and Research, 16(1), 21-33.

Kymlicka, Will y Norman, Wayne (1997). El retorno del ciudadano. Una revisión de la producción reciente en la teoría de la ciudadanía. Ágora, 7, 5-42.

Marston, Sallie y Mitchell, Katharyne (2004). Citizens and the State: Citizenship Formations in Space and Time. En Barnet, Clive yLow, Murray (Eds.), Spaces of Democracy. Geographical Perspectives on Citizenship, Participation and Representation (pp. 93-112). London: Sage.

Pérez Mendoza, Sofía (2018, 14 de septiembre). La justicia anula la venta de otras siete viviendas vendidas por la Comunidad de Madrid a un fondo buitre en 2013. El Diario. Recuperado el 3 de octubre de 2018 de: https:/ / www.eldiario.es/ma$\mathrm{drid} /$ justicia-revierte-viviendas-Comunidad-Madrid_0_814368778.html.

Landa, Sergio Rubén (2005). Ciudadanía responsable: Asambleas populares en la ciudad de La Plata [Tesis de 
grado]. Facultad de Humanidades y Ciencias de la Educación, Universidad Nacional de La Plata. Recuperado el 3 de marzo de 2021 de: http:/ /www.memoria.fahce.unlp.edu.ar/tesis/te.625/te.625.pdf.

Leitner, Helga y Strunk, Christopher (2014). Assembling insurgent citizenship: immigrant advocacy struggles in the Washington DC metropolitan area. Urban Geography, 35(7), 943-964. DOI: 10.1080/02723638.2014.943582.

López, Emiliano y Ducid, Manuel (2016). La conformación de una hegemonía desarrollista en la Argentina post-neoliberal. Revista mexicana de sociología, 78(2), 229-255. DOI: http://dx.doi. org/10.22201/iis.01882503p.2016.2.55100.

Mignolo, Walter D. (2006). Citizenship, knowledge, and the limits of humanity. American Literary History, 18(2), 312-331. DOI: https://doi.org/10.1093/ alh/ajj019.

Mitchell, Katharyne (2003). Educating the National Citizen in neoliberal Times: From the Multicultural Sefl to the Strategis Cosmopolitan". Transactions of the Institute of British Geographers, 28(4), 387-403. DOI: https://doi.org/10.1111/j.00202754.2003.00100.x.

Mitchell, Katharyne, Sallie Marston y Cindi Katz (2003). Introduction: Life's Work: An Introduction, Review and Critique. Antipode, 35(3), 415-442. DOI: https://doi.org/10.1111/1467-8330.00333.

Motta, Jorge Martín, Paula Cecilia Rosa y Ariel Oscar García (2013). Perspectivas y tensiones del espacio público: los habitantes de la calle en la Ciudad Autónoma de Buenos Aires. Cuaderno Urbano. Espacio, Cultura, Sociedad, 15(15), 49-69. DOI: http:// dx.doi.org/10.30972/crn.1515516.

Mouffe, Chantal (1999). El retorno de lo político. Comunidad, ciudadanía, pluralismo, democracia radical. Buenos Aires: Paidós.

Natalucci, Ana (2011). Entre la movilización y la institucionalización: Los dilemas de los movimientos sociales (Argentina, 2001-2010). Polis, 10(28), 193219.

Ouviña, Hernán (2008). Las asambleas barriales y la construcción de lo "público no estatal": la experiencia en la Ciudad Autónoma de Buenos Aires. En Levy, Bettina, Natalia Gianatelli y Dolores Calvo (Eds.), La política en movimiento. Identidades y experiencias de organización en América Latina (pp. 65102). Buenos Aires: CLACSO.

Ouviña, Hernán (2009). La autonomía urbana en territorio argentino. Apuntes en torno a la experiencia de las asambleas barriales, los movimientos piqueteros y las empresas recuperadas. En Bonet,
Alberto y Adrián Piva (Eds.), Argentina en Pedazos (pp. 115-143). Buenos Aires: Ediciones Continente.

Pousadela, Inés María (2011). Entre la deliberación politica y la terapia de grupo la experiencia de las asambleas barriales-populares en la Argentina de la crisis. Buenos Aires: CLACSO.

Quintar, Aída y Zusman, Perla (2003). ¿Emergencia de una multitud constituyente? Resonancias de las jornadas de diciembre de 2001 en Argentina. Íconos. Revista de Ciencias Sociales, 17, 58-68. DOI: https://doi.org/10.17141/iconos.17.2003.495.

Rajland, Beatriz y Campione, Daniel (2006). Piqueteros y trabajadores ocupados en la Argentina de los últimos años: novedades y continuidades en su participación y organización en los conflictos. En López Maya, Margarita (Ed.), Sujetos sociales y nuevas formas de protesta en la historia reciente de América Lati$n a$ (pp. 297-330). Buenos Aires: CLACSO.

Retamozo, Martín (2011). Movimientos sociales, política y hegemonía en Argentina. Polis. Revista de la Universidad Bolivariana, 10(28), 243-279. Recuperado de el 5 de diciembre de 2021 de: http:/ /www. memoria.fahce.unlp.edu.ar/art_revistas/pr.7435/ pr.7435.pdf.

Rodríguez, María Carla y María Cecilia Zapata (2020). Organizaciones sociales y autogestión del hábitat en contextos urbanos neoliberales. Íconos. Revista de Ciencias Sociales, 67. DOI: https://doi. org/10.17141/iconos.67.2020.3964.

Rossi, Federico Matías (2005). Aparición, auge y declinación de un movimiento social: las asambleas vecinales y populares de Buenos Aires, 2001-2003. Revista Europea de Estudios Latinoamericanos y del Caribe, 78, 67-88.

Staeheli, Lynn y Mitchell, Don (2007). Locating the public in research and practice. Progress in $\mathrm{Hu}$ man Geography, 31(6), 792-811. DOI: https://doi. org $/ 10.1177 / 0309132507083509$.

Svampa, Maristella (2008). El final del kirchnerismo. New Left Review, 53, 73-88.

Svampa, Maristella (2011). Argentina, una década después. Del "que se vayan todos" a la exacerbación de lo nacional-popular. Nueva Sociedad, 235, 17-34.

Svampa, Maristella y Damián Corral (2006). Political Mobilization in Neighborhood Assemblies: The Cases of Villa Crespo and Palermo. En Epstein, Edward y Pion-Berlin, David (Eds.), Broken Promises? The Argentine Crisis and Argentine Democracy (pp. 117139). Lanham: Lexington Books.

Triandafyllidou, Anna (1998). National Identity and the "Other". Ethnic and Racial Studies, 21(4), 593613. 
Farías, Mónica y Torres, Fernanda Valeria (2021). Construir la ciudadanía colectivamente: prácticas urbanas de una asamblea popular en Buenos Aires, Argentina. Hábitat y Sociedad, 14, 11-31. <https://doi.org/10.12795/HabitatySociedad.2021.i14.02> 


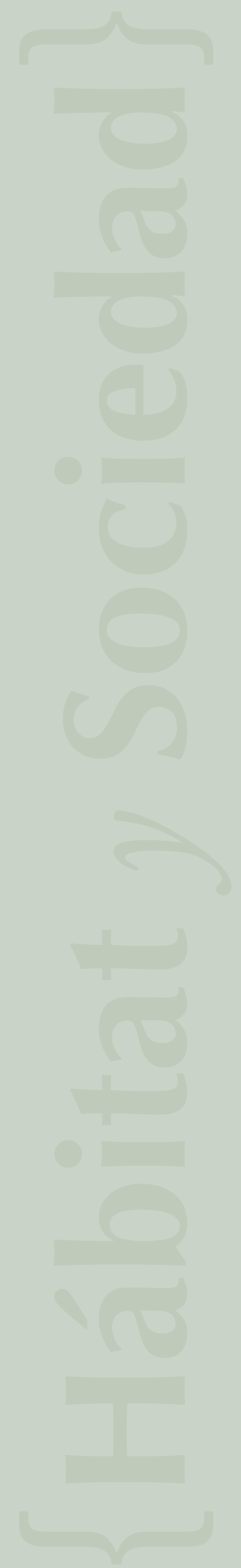

